\title{
Primary Systemic Anaplastic Large Cell Lymphoma, ALK-Positive
}

National Cancer Institute

\section{Source}

National Cancer Institute. Primary Systemic Anaplastic Large Cell Lymphoma, ALK-

Positive. NCl Thesaurus. Code C37195.

A T-cell peripheral lymphoma affecting multiple anatomic sites. It is composed of usually large, pleomorphic, CD30 positive T-lymphocytes with abundant cytoplasm. It is characterized by the presence of a translocation involving the ALK gene and expression of ALK fusion protein. 